\title{
Research on the Innovative Development of Martial Arts Tourism Economy in Hubei Province under Internet+ Mode
}

\author{
Yi Ke ${ }^{1, *}$ \\ ${ }^{1}$ School of Physical Education and Equestrian, Wuhan Business University, Wuhan, China
}

\begin{abstract}
Sports tourism is generally regarded as a new growth point for economic development, and is gradually becoming a new way of life and leisure for people. Although Hubei is a province with rich tourism resources and a long history of martial arts, the pace of development of martial arts tourism industry as a whole is rather slow. Through the methods of literature and field research, the author has studied the martial arts tourism industry in Hubei Province and has proposed development strategies and approaches from the perspective of Internet+, emphasizing the need for innovative thinking and initiatives to promote the development of the martial arts tourism economy in Hubei Province.
\end{abstract}

\section{Introduction}

In recent years, in order to accelerate the development of fitness and leisure industry and further promote the development of sports industry including sports tourism, the State Council, the General Administration of Sport fo China (GASC) and the National Tourism Administration (NTA) have issued several documents to provide strong support and guarantee. In May 2016, NTA and GASC signed the Cooperation Agreement on Promoting the Integrated Development of Sports Tourism. In October, the State Council issued the Guidance Opinions of the General Office of the State Council on Accelerating the Development of Fitness and Leisure Industry. In November, the State Council issued the Opinions on Further Expanding Consumption in Tourism, Culture, Sports, Health, Pension, Education and Training. In December, NTA and GASC jointly issued the "Guidance Opinions on Vigorously Developing Sports Tourism". In July 2017, they jointly held the first national sports tourism industry development conference in history.

Under the guidance of the concept of strong sports and healthy China, the people's demand for diversified sports and tourism and leisure is growing fast, and the industrial development has formed a considerable market scale. Sports tourism has become an important leisure lifestyle with broad future prospects.

With the care and support of the central government, Hubei revived its economy after the epidemic and recovered rapidly, with a regional GDP of 4,344.346 billion yuan in 2020, ranking eighth in the country. In May 2020, the People's Government of Hubei Province issued a document entitled "Several Measures to Support the Recovery and Revitalization of the Cultural Tourism Industry". From August 8 to December 31, 2020, Hubei Province held the "Walk with Love, Tour Hubei" campaign, in which the province's A-class tourist attractions were free of admission fees for tourists nationwide, driving the recovery and development of the entire tourism market chain.

In February 2021, Hubei Province released the Notice on the Implementation Rules of Several Measures to Support the Recovery and Revitalization of the Cultural Tourism Industry, which focuses on 34 items in 16 areas to fully promote Hubei's post-epidemic revitalization and high-quality development. The economic rise and policy support of Hubei province has created a good environment for the development of sports tourism.

\section{Current situation of martial arts tourism industry in Hubei Province}

\subsection{Advantages}

\subsubsection{Long history and distinctive characteristics of martial arts}

Jingchu culture is a long-standing and profound culture, an important part of Chinese culture, with distinctive regional characteristics and far-reaching cultural influence. Hubei is the birthplace of Jingchu culture and the political, economic and cultural center of the ancient state of Chu. As a part of the Jingchu culture, Hubei martial arts plays a very important role in the development of Chinese martial arts. Located in the central part of the country, the martial arts techniques in Hubei have evolved and developed on the basis of the fusion of northern and southern styles, forming a series of distinctive and rich styles. The top brand of Hubei martial arts is the famous Wudang martial arts, and there are some other wellknown styles such as Yumen boxing popular in Wuhan, Jingzhou, Qianjiang and other areas, Yuejia boxing in Huanggang area and Tujia martial arts in southwest of

\footnotetext{
*Corresponding author: 623256467@qq.com
} 
Hubei. Nowadays, Hubei Province has 13 national and provincial martial arts "non-heritage" listed items [1].

\subsubsection{Strong Momentum of Wushu Tourism Development}

Taking Wudang Mountain in Hubei as an example, a large number of domestic and foreign tourists come to visit Wudang Mountain every year, including a large number of Wudang martial arts enthusiasts who visit there in groups. The mysterious and spiritual Wudang martial arts and the legendary story of Zhang Sanfeng, the Taoist priest of Wudang Mountain, who founded Taijiquan, are some of the main factors for these people to come to Wudang Mountain for tourism and consumption. This, coupled with the exquisite religious complexes and Taoist culture of Wudang Mountain, has made the region unique in its tourism appeal, resulting in an endless stream of visitors each year, with the number of visitors to Wudang Mountain exceeding the 10 million person times in 2019 [2]. Although the martial arts tourism industry in Wudang Mountain is not yet mature and strong enough, it has already gained initial success and is moderately famous. The fact tells us that the development potential of the martial arts tourism industry is huge and there are many good projects that can be done.

\subsubsection{Outstanding geographical location and convenient transportation network}

Hubei Province is located in the middle reaches of Yangtze River, connected to Anhui in the east, Jiangxi and Hunan in the south, Chongqing in the west, Shaanxi in the northwest and Henan in the north, which is the central point of China. Wuhan, the provincial capital, is the largest water, land and air transportation hub in China's inland, especially the highly developed high-speed railway network, which radiates the whole country and spreads to all the surrounding cities in the province, which will not only strengthen the transportation strength of the surrounding cities and enhance their functions, but also strongly support the development of sports tourism industry in each city.

As a prefecture-level city and a city with relatively good development of martial arts tourism industry, Hubei's Shiyan, has a three-dimensional rapid transportation network with four railway stations and one airport. The rapid transportation network built by the civil aviation, high-speed railway and expressway not only helps to enhance the popularity of Wudang Mountain scenic spot, but also improves the travel experience and tourism quality of tourists, which is significant and has far-reaching impact on promoting the development of martial arts tourism industry.
Table1. Overview of Shiyan Railway Station and Airport

\begin{tabular}{|c|c|c|c|}
\hline No. & Name & $\begin{array}{c}\text { Construction } \\
\text { and operation }\end{array}$ & Scale \\
\hline 1 & $\begin{array}{l}\text { Shiyan } \\
\text { Railway } \\
\text { Station }\end{array}$ & $\begin{array}{l}\text { Built in } \\
\text { December } 1971\end{array}$ & $\begin{array}{c}2 \text { platforms, } 7 \\
\text { lines }\end{array}$ \\
\hline 2 & $\begin{array}{l}\text { Shiyan Dong } \\
\text { Railway } \\
\text { Station }\end{array}$ & $\begin{array}{l}\text { started in Feb. } \\
\text { 2016, operating } \\
\text { from Nov. } 2019\end{array}$ & $\begin{array}{c}3 \text { platforms, } 7 \\
\text { lines, (6 platforms } \\
\text { and } 18 \text { lines } \\
\text { reserved) }\end{array}$ \\
\hline 3 & $\begin{array}{l}\text { Wudang } \\
\text { Shan } \\
\text { Railway } \\
\text { Station }\end{array}$ & Built in 1968 & $\begin{array}{c}2 \text { platforms, } 17 \\
\text { lines }\end{array}$ \\
\hline 4 & $\begin{array}{l}\text { Wudang } \\
\text { Shan Xi } \\
\text { Railway } \\
\text { Station }\end{array}$ & $\begin{array}{l}\text { started in Jul. } \\
\text { 2018, operating } \\
\text { from Nov. } 2019\end{array}$ & $\begin{array}{c}2 \text { platforms, } 4 \\
\text { lines }\end{array}$ \\
\hline 5 & $\begin{array}{l}\text { Shiyan } \\
\text { Wudang } \\
\text { Shan Airport }\end{array}$ & $\begin{array}{l}\text { Officially } \\
\text { opened to traffic } \\
\text { in February } \\
2016 \\
\end{array}$ & $\begin{array}{c}\text { 2,800 Chinese } \\
\text { acres, } 24 \text { routes to } \\
32 \text { cities }\end{array}$ \\
\hline 6 & $\begin{array}{l}\text { Zhu Shan } \\
\text { County } \\
\text { General } \\
\text { Aviation } \\
\text { Airport }\end{array}$ & $\begin{array}{l}\text { Planned, } \\
\text { upcoming } \\
\text { construction }\end{array}$ & $\begin{array}{l}\text { The planning area } \\
\text { is } 974 \text { Chinese } \\
\text { acres, } 1 \text { runway } \\
\text { set at } 1800 \text { meters }\end{array}$ \\
\hline
\end{tabular}

\subsection{Problems and shortcomings}

\subsubsection{Regional unevenness and inadequacy in the development of martial arts tourism}

Table2. List of National Intangible Cultural Heritage of Wushu in Hubei Province

\begin{tabular}{|c|c|c|c|}
\hline No. & Name & Announcement Date & Filing Area \\
\hline 1 & $\begin{array}{c}\text { Wudang } \\
\text { Wushu }\end{array}$ & 2006 (First batch) & Shiyan City \\
\hline 2 & $\begin{array}{c}\text { Yuejia } \\
\text { Quan }\end{array}$ & 2008 (Second batch) & Wuxue city \\
\hline 3 & $\begin{array}{c}\text { Yuejia } \\
\text { Quan }\end{array}$ & 2014 (Fourth batch) & $\begin{array}{c}\text { Huangmei } \\
\text { County }\end{array}$ \\
\hline
\end{tabular}

As can be seen from the above table, there are three national-level intangible cultural heritage of martial arts in Hubei Province. Among them, Wudang Wushu has the greatest fame and the best development. This is related to the long history and cultural accumulation of Wudang Wushu, but undoubtedly, it also has a very important correlation with the high priority Shiyan government attaches to the development of the region. As early as 2010, Shiyan publicly stated that it would strive to make Wushu the city card, and in recent years, the number of tourists visiting Wudang Mountain to experience Wudang martial arts and Taoist culture has been soaring year by year. However, it is also noticeable that some other regions in Hubei with deep roots in martial arts heritage and notable potential have been sluggish in the development of martial arts tourism industry. Wuhan, in particular, has various foundations for the development of 
the martial arts tourism industry, such as a well-developed service industry, a rich martial arts culture, and a large number of excellent martial arts professionals trained by well-known local universities, but there is no martial arts tourism industry that can be reputed, which is indeed a great pity.

\subsubsection{The promotional means of using the new Internet media are not adequate, not strong enough and not effective}

After entering the Internet era, many industries have adopted a combination of online and offline promotion mode, and martial arts is no exception. Taking Wudang Wushu as an example, it is often seen in newspapers, magazines, TV and other print media and online media, but compared with Songshan Shaolin Temple in Henan Province, which also features martial arts as a tourist attraction, the gap is very obvious.

For example, the martial arts community has always had the saying "North respect Shaolin, South respect Wudang", but the influence of Shaolin Temple, whether in literature, film and television dramas, or in reality, is better than Wudang Mountain. According to the latest website ranking of chinaz.com in June 2021, the official website of Wudang Mountain is in an overall backward situation compared with the Shaolin Temple's official website, in terms of comprehensive data. In addition, in the famous video platform Tiktok, With "Wudang Mountain" as the keyword search, the number of fans of the top 3 Tiktok accounts were: 802,000, 282,000 113,000. And with "shaolin temple" as the keyword search, the number were: 4.185 million, 3.799 million, 1.3 million. These show in a certain way that the Wudang Mountain online promotion platform is not attractive enough, the means of publicity is not innovative enough and the influence is relatively limited.

Table3. Wudang Shaolin official website ranking data comparison table

\begin{tabular}{|c|c|c|c|c|}
\hline No. & Website & $\begin{array}{c}\text { Total } \\
\text { ranking }\end{array}$ & $\begin{array}{c}\text { Province } \\
\text { ranking }\end{array}$ & $\begin{array}{c}\text { Alexa } \\
\text { ranking }\end{array}$ \\
\hline 1 & wudangshan.gov.cn & 21199 & 506 & $\begin{array}{c}144 \\
\text { million }\end{array}$ \\
\hline 2 & shaolin.org.cn & 8253 & 161 & $\begin{array}{c}53 \\
\text { million }\end{array}$ \\
\hline
\end{tabular}

\subsubsection{Fierce competition from other provinces in the tourism industry}

Taking Henan Province, a large population and economic province adjacent to Hubei Province and also a large martial arts province, as an example, the province vigorously promotes the development of martial artsrelated industries and has made impressive achievements in the martial arts tourism industry. Dengfeng, a small city more than 80 kilometers from Zhengzhou, the capital of Henan Province, has taken advantage of the extensive influence of Shaolin Temple and Shaolin martial arts at home and abroad to embark on a road to martial arts industrialization and achieved great success. As early as 2017, Songshan Shaolin scenic area tourist reception has exceeded 3.5 million [3], Dengfeng city fully use the Shaolin Temple martial arts elements, vigorously create a Shaolin Kung Fu Tour international tourism IP with global market influence radiation.

In addition to this, in order to continuously expand its market share, Henan Province has taken equally strong measures in other provincial cities to vigorously develop the martial arts tourism industry. Henan TV, headquartered in Zhengzhou, launched a high-end martial arts combat event "Wulin Feng" in 2004, and after years of development, it has gone into more than ten countries and regions to organize competitions and performances, spreading its international reputation far and wide, becoming an international combat organization and communication platform with a distinctive Chinese trademark. Zhengzhou has also seized the opportunity to establish a Wulin Feng training base and the Zhengzhou International Martial Arts Cultural Industry Expo to further develop martial arts-related industries.

Another example is Jiaozuo city of Henan. As the birthplace of the Chen's style of Taijiquan, Jiaozuo is also making great efforts in the martial arts tourism industry. The leaders of Jiaozuo once led a delegation to visit the United Nations headquarters in New York, and held a tourism promotion meeting in New York for Jiaozuo to strengthen the image promotion of martial arts tourism and expand the international tourist market. And for the first time, two tourism promotion centers of "the birthplace of Chinese Taijiquan" were set up in Los Angeles and Toronto to strongly promote the brand of Jiaozuo martial arts tourism [4]. Under such circumstances, apart from Wudang Mountain, it is difficult for Hubei Province to have other comparable martial arts tourism industry to rival with. Therefore, the competitive pressure faced by Hubei Province in the development of martial arts tourism industry is huge.

\section{Strategies and pathways for development}

\subsection{All-out effort to create a live video promotion platform for martial arts tourism in the Internet+ era}

In the Internet + era, portals, microblogging, WeChat, network forums, etc., although they are not the past tense of network advertising platform, but they are no longer the mainstream of network traffic to play. It can be said that if you want to do a good job of advertising you must seize the network traffic, and if you want to seize the network traffic you must be good at making promotional videos. For example, a young girl named Ma Zhao Lingyun often posts original video clips on the Tik-Tok short video app [5], and her works are mainly themed on Emei martial arts. The number of followers of her Tik-Tok account named "Ling Yun" has so far exceeded 10 million and reached over 120 million likes, causing domestic and international media to scramble for coverage and greatly promoting the globalization of Emei martial arts.

Hubei must grasp the new situation and changes in the development of the Internet, and do a good job of 
promoting martial arts tourism on live video platforms, such as launching a series of promotional works, or supporting the cultivation of high-quality video anchor stars and martial arts tourism promotion ambassadors, etc., with sustained and precise efforts to expand the publicity effect.

\subsection{Integrating and promoting Hubei martial arts tourism resources with high-quality software}

The first thing to do is to integrate and excavate the province's advantages of martial arts tourism resources and elements, design and develop high-quality APP software for martial arts tourism on this basis, strengthen the APP function layout focusing on providing good services for martial arts tourism in Hubei, and promote the application through multiple channels to further expand the influence of Hubei's martial arts tourism market. We may also utilize the existing APP platform to deeply embed martial arts tourism elements, such as designing and developing small programs with friendly interface and convenient use for mainstream social APPs such as WeChat, Weibo, to continuously keep Hubei martial arts tourism a hot topic on social networks.

\subsection{Deep cooperation with OTA enterprises to improve Hubei martial arts tourism service level}

Currently many industries have developed to deep Internetization, the most obvious sign of the Internetization of travel services and travel market is the rise of OTAs. OTA stands for Online Travel Agency, which is an internet-based online consumer market for purchasing and booking tourism service products, as well as the function of providing tourism information. Tourists can enjoy online one-click booking, payment and complete travel planning at OTAs, and their market share in the tourism sector is increasing year by year.

The martial arts tourism industry can strengthen cooperation with Ctrip, Tuniu, Flying Pig and other mainstream OTA enterprises, and deepen cooperation in martial arts event and performance registration, service booking, martial arts peripheral products ordering, and tourists' experience feedback, etc. Targeted customized services and sales projects can not only further promote industry development, but also continuously improve martial arts tourism service level and optimize tourists' experience through OTAs.

\subsection{Improving tourism experience by using big data and artificial intelligence technologies}

By collecting and organizing tourists' data through big data technology, analyzing and comparing data on their itineraries, subscriptions and interactions, and using the data results to understand tourists' interest points and consumption preferences in participating in martial arts tourism, we can provide references for operation and management departments to optimize services, improve tourism resource allocation and build tourism service supporting facilities. At the same time, the data results should be compared and analyzed with the expected results to provide the basis for strategic design and marketing decisions of martial arts tourism.

In large martial arts events and performances, artificial intelligence technologies such as flow guidance, intelligent navigation, convenient ticketing and face recognition can be used to improve the service feeling and optimize the experience of tourists participating in martial arts tourism projects. One can also try to open customized martial arts VR scenes in airports, stations, scenic spots, hotels, restaurants and performing venues, etc., using VR and AR technologies to attract tourists and promote martial arts tourism projects.

\subsection{Targeted support for the development of wushu tourism industry in areas with great potentials}

There are many places with great potential in Hubei for developing martial arts tourism industry in addition to Wudang Mountain such as Wuhan, Enshi and Yichang. These cities have both well-known martial arts histories and are also famous tourist cities. Wuhan is a national tourist city and has first-class city facilities, Enshi has Tujia culture and a large number of scenic spots, and Yichang is extremely rich in tourism resources, with more than 400 tourist attractions.

Hubei tourism authorities should support these potential, advantageous cities to promote the development of martial arts tourism industry, by strengthening crossover cooperation with emerging leisure tourism industry such as recreation bases, cultural tourism towns and resort scenic spots in the region, deeply integrating martial arts elements with tourism and leisure and recreation experience, providing rich and diversified service supply, and aiming for at least one martial arts tourism brand in one city.

\section{Conclusion}

With the steady development of China's economy, as a tertiary industry, the services industry has grown by leaps and bounds and has now become one of the most important industries in the national economy. Furthermore, China is now in the decisive stage of building a moderately prosperous society, and service industries such as sports and leisure tourism have been considered as highly advantageous new growth points for the economic development. In the face of the favourable policies and in the context of the era of Internet+ development, Hubei's martial arts tourism industry has a broad prospect. It is essential to seize the opportunity, combine the existing advantages of the potential development area, and innovate initiatives with Internet thinking to effectively get Hubei's martial arts tourism industry up to a competitive and appealing position nationwide, and eventually become a new highlight in the transformation and upgrading of Hubei's sports industry development. 


\section{References}

1. Song Jianbo." Research on the protection and inheritance of traditional martial arts in Hubei under the threshold of "non-heritage"." Martial Arts Research6.03(2021):68-71. doi:10.13293/j.cnki.wskx.008865.

2. Shiyan Broadcasting network, Breaking the 10 million mark for the first time! Wudang Mountain receives 10.3 million visitors in 2019, 2020.1, https://www.syiptv.com/article/show/112105

3. Henan Travel News Express, Visitors to Shaolin Scenic Area exceeded 3.5 million in 2017, and the 2018 "China Shaolin Kung Fu Tour" was officially launched,2018.2,

https://www.sohu.com/a/220554769_722055

4. Chinese Taijiquan Elite Network, 2017.6, The Birthplace of Taiji in China - Jiaozuo Tourism (New York) Promotion Conference was successfully held, http://www.taiji168.com/news/zgtjqfydjzlynytjhcgjb 2280_1.html

5. Du Yubin, et al. "Advantages, problems and development paths of traditional martial arts tiktok short video communication in the new media era." Hubei Sports Science and Technology 39.12 (2020): 1071-1075. doi:CNKI:SUN:HYKJ.0.2020-12-010. 